\title{
PROGRAM KEMITRAAN MASYARAKAT: OPTIMALISASI PAUD HOLISTIK DI DESA LEMAHMULYA KECAMATAN MAJALAYA KABUPATEN KARAWANG
}

\author{
Nelly Apriningrum ${ }^{1)}$ dan Maria Alia Rahayu ${ }^{2)}$ \\ ${ }^{1,2}$ Kebidanan, Fakultas Ilmu Kesehatan, Universitas Singaperbangsa Karawang \\ ${ }^{1,2}$ Jl. HS. Rongowaluyo Telukjambe Timur, Karawang, 41361 \\ E-mail : nelly.apriningrum@fkes.unsika.ac.id ${ }^{1)}$, marialia_rahayu@yahoo.com ${ }^{2)}$
}

\begin{abstract}
ABSTRAK
Pembangunan kesehatan salah satunya dilakukan melalui upaya peningkatan kesehatan anak sejak masih di dalam rahim selama lima tahun pertama kehidupan. Pelayanan posyandu sebagai unit kesehatan berbasis masyarakat yang ada selama ini masih berfokus pada pelayanan penimbangan berat badan, pemberian vitamin A dan imunisasi serta cenderung mengabaikan pemantauan perkembangan balita. Hal ini juga terjadi di Desa Lemahmulya Kecamatan Majalaya. Adanya permasalahan tersebut diperlukan solusi dengan mengintegrasikan pelayanan Pendidikan Anak Usia Dini (PAUD) dengan pelayanan posyandu dan Bina Keluarga Balita (BKB) melalui kegiatan pengabdian masyarakat berupa optimalisasi PAUD Holistik. Sasaran kegiatan ini adalah dengan memberikan pelatihan kepada para guru PAUD, kader posyandu dan BKB tentang konsep pertumbuhan dan perkembangan balita, pemantauan dan deteksi dini adanya penyimpangan sehingga diharapkan dapat memberikan pelayanan PAUD secara holistik.

Metode pelaksanaan kegiatan pengabdian ini menggunakan metode penyelesaian masalah melalui pendekatan partisipatif. Hasil dari kegiatan pengabdian ini berupa terjalinnya kerjasama antar kader melalui pelayanan integrasi, peningkatan pengetahuan kader tentang pertumbuhan dan perkembangan balita, menunjang terlaksananya kegiatan pengabdian dengan memberikan investasi Stimulasi, Deteksi dan Intervensi Dini Tumbuh Kembang (SDIDTK) kit serta implementasi Optimalisasi PAUD holistik di Desa Lemahmulya. Potensi tokoh masyarakat, kader dan masyarakat yang ada menjadi peluang agar kegiatan PAUD Holistik ini dapat dilaksanakan secara berkelanjutan.
\end{abstract}

Kata Kunci: Bina Keluarga Balita, Balita, Holistik, Pendidikan Anak Usia Dini, Posyandu, Desa Lemahmulya

\section{PENDAHULUAN}

Pembangunan kesehatan salah satunya diselenggarakan melalui upaya peningkatan kesehatan sejak anak masih didalam kandungan hingga lima tahun pertama kehidupannya dengan tujuan menghasilkan generasi penerus yang sehat dan selamat saat kelahirannya. Selain itu juga untuk meningkatkan kualitas hidup anak agar mencapai tumbuh kembang yang optimal baik fisik, mental, emosional, sosial serta intelegensi sesuai potensi genetiknya. (Kementerian Kesehatan RI 2016).

Pembinaan tumbuh kembang anak terintegrasi dan berkualitas diselenggarakan melalui program kegiatan stimulasi, deteksi dini dan intervensi terhadap penyimpangan tumbuh kembang balita yang dilakukan pada masa kritis. Masa balita dikenal dengan "golden periode" dan "window of opportunity", masa yang sangat peka terhadap lingkungan serta tidak dapat diulang kembali (Kementerian Kesehatan RI 2016).

Upaya pemerintah melalui kementrian kesehatan dengan menyelenggarakan program stimulasi, deteksi dini dan intervensi terhadap penyimpangan tumbuh kembang balita secara komprehensif dan berkoordinasi antara keluarga, masyarakat, tokoh masyarakat, organisasi profesi (pendidik), lembaga swadaya masyarakat dengan tenaga professional kesehatan yang bekerja di lini terdepan serta petugas sektor swasta lainnya.

Kegiatan posyandu balita sebagai unit kesehatan berbasis masyarakat (UKBM) di Desa Lemahmulya Kecamatan Majalaya yang selama ini dilakukan masih belum menyentuh aspek pemantauan tumbuh kembang secara komprehensif, masih terfokus hanya pada pemantauan pertumbuhan seperti penimbangan berat badan, dan pelayanan kesehatan seperti imunisasi dasar, pemberian vitamin A dan obat cacing pada anak (Sukesi et al, 2011; Suryanto, Purwandari H 2014).

Upaya agar anak dapat tumbuh dan berkembang secara optimal dengan melakukan deteksi terhadap penyimpangan dan intervensi dini. Upaya ini perlu dilaksanakan oleh semua pihak dari tingkat keluarga, petugas kesehatan mulai dari kader kesehatan sampai dokter spesialis, dan di tingkat pelayanan kesehatan mulai dari tingkat dasar sampai pelayanan spesialis. Posyandu sebagai bentuk partisipasi masyarakat merupakan salah satu wadah pelayanan kesehatan 
masyarakat yang paling dasar. Hasi survey pendahuluan di desa Lemah Mulya terdapat 8 posyandu dengan jumlah balita sebanyak 456 balita. Pencapaian target kehadiran ke posyandu cukup baik mencapai $80 \%$, namun pelayanan yang posyandu berikan baru terbatas pada pada aspek pertumbuhan saja serta cenderung mengabaikan aspek perkembangan yang tidak kalah penting.

Mengatasi permasalahan diatas, maka diperlukan program terintegrasi pemeliharaan kesehatan, pemenuhan kebutuhan gizi, perlindungan, pengasuhan dan Pendidikan. Pembinaan tumbuh kembang anak diintegrasikan dengan Pendidikan Anak Usia Dini (PAUD) sebagai Pendidikan tahapan kelompok bermain dan Taman Kanak-Kanak (TK) yang saat ini banyak diikuti oleh para balita sebelum memasuki jenjang pendidikan Sekolah Dasar (SD). Dalam hal ini orang tua, kader dan guru PAUD merupakan elemen penting yang dapat mengetahui adanya penyimpangan tumbuh kembang serta intervensi yang tepat pada usia dini, namun demikian terdapat beberapa kendala yang dihadapi oleh guru PAUD dan kader posyandu dalam melaksanakanan kegiatan SDIDTK, diantaranya kurangnya pengetahuan dan ketrampilan guru dan kader serta belum dimilikinya alat SDIDTK yang memadai.

Untuk mengatasi berbagai kendala tersebut diperlukan pengembangan PAUD yang bekerjasama dengan posyandu serta BKB untuk meningkatan pengetahuan dan keterampilan guru maupun kader dalam pelaksanaan kegiatan pemantauan tumbuh kembang serta penyediaan alat atau sarana untuk mendukung kegiatan. Melalui pengabdian kepada masyarakat ini diharapkan dapat menjalin kerjasama untuk mengoptimalkan potensi yang ada dimasyarakat melalui "Optimalisasi PAUD Holistik di Desa Lemah Mulya Kecamatan Majalaya Kabupaten Karawang" melalui pelatihan bagi kader, investasi alat permainan edukatif serta implementasi pelayanan PAUD holistik.

\section{RUANG LINGKUP}

Ruang lingkup permasalahan pada pengabdian ini meliputi terbatasnya pelayanan PAUD, pengetahuan dan keterampilan kader tentang pertumbuhan dan perkembangan balita yang terbatas. Diharapkan hasil pengabdian dapat mengoptimalkan pelayanan PAUD agar terintegrasi dengan pelayanan posyandu, sehingga kebutuhan menyeluruh bagi balita terpenuhi baik pertumbuhan, kebutuhan gizi, imunisasi, perkembangan motorik kasar, halus, kemandirian sosial serta sosialisasi dan bahasa. Melalui kegiatan pengabdian berupa pelatihan dan refreshing bagi para kader diharapkan dapat meningkatkan pengetahuan dan keterampilan para kader dalam menjalankan tugas dan tanggungjawabnya memberikan pelayanan kepada masyarakat. Selain itu diharapkan para orangtua sebagai orang terdekat dan pengasuh balita memahami kebutuhan yang akan berdampak pada perkembangan kehidupan selanjutnya.
Hasil pengabdian masyarakat ini berupa artikel ilmiah yang dipublikasikan pada jurnal pengabdian.

\section{BAHAN DAN METODE}

Disajikan bahan kajian teoritis dan metode dalam kegiatan pengabdian ini

\subsection{Kajian Empirik}

Hasil penelitian yang dilakukan oleh Iswarawanti dengan judul Kader Posyandu : Peranan dan Tantangan Pemberdayannya dalam Usaha Peningkatan Kesehatan Gizi Anak di Indonesia yang menyatakan bahwa perlunya pemberdayaan kader kesehatan sebagai upaya solusi komprehensif dan sistematik untuk mendukung pemerintah yang kurang optimal dalam program revitalisasi posyandu (Iswarawanti, 2010)

Penelitian lain oleh Sabarini S dkk tentang Desain Pengembangan Anak Usia Dini Holistik Integratif PAUD Non Formal dengan menggunakan metode penelitian Research and Development yang menyatakan bahwa desain PAUD holistik yang terintegrasi dengan posyandu dan BKB sangat efektif dibandingkan dengan pelayanan PAUD yang dilakukan oleh posyandu atau BKB secara sendiri-sendiri (Sabarini S, 2013).

Hasil penelitian lain oleh Hidayati $U$ mengenai Pendidikan Holistik Integratif di Roudhotul Athfal dengan menggunakan metode penelitian kualitatif melalui pendekatan fenomenologi dan sosio historis bahwa penyelenggaraan PAUD holistik integratif melalui program pembelajaran, layanan pendidikan, layanan kesehatan dan gizi seimbang, pengasuhan dan perlindungan berjalan dengan baik dan cukup berhasil (Hidayati U, 2017)

\subsection{Tahap Pelaksanaan}

Tahap ini diawali dengan permohonan izin kepada kepala desa dan kepala puskesmas setempat dalam rangka pelaksanaan kegiatan pengabdian, menyampaikan tujuan serta permohonan dukungan. Selanjutnya penyampaian maksud dan tujuan kepada pihak terkait yang terdiri dari kepala sekolah PAUD, bidan desa serta para kader. Selain itu kegiatan ini juga melibatkan 10 mahasiswa kebidanan untuk dapat mengaplikasikan teori yang didapat dikampus kepada masyarakat. Tahap persiapan sebagaimana gambar 1 .

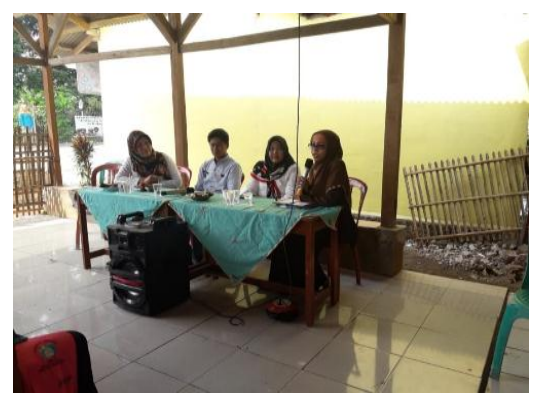

Gambar 1. Permohonan Izin kepada Pemangku Kebijakan dan Masyarakat Desa Lemahmuya 
Pelaksanaan kegiatan pengabdian ini menggunakan pendekatan penyelesaian masalah berdasarkan kesepakatan antara tim pengabdian dengan mitra melalui pendekatan partispatif, yang meliputi : Metode diskusi/ konsultasi untuk mengkoordinasikan pelayanan posyandu dengan PAUD agar terjalin kerjasama pelayanan integrasi, pemilihan dan pembentukan kader BKB (Bina Keluarga Balita) sebagaimana terlihat pada gambar 2.

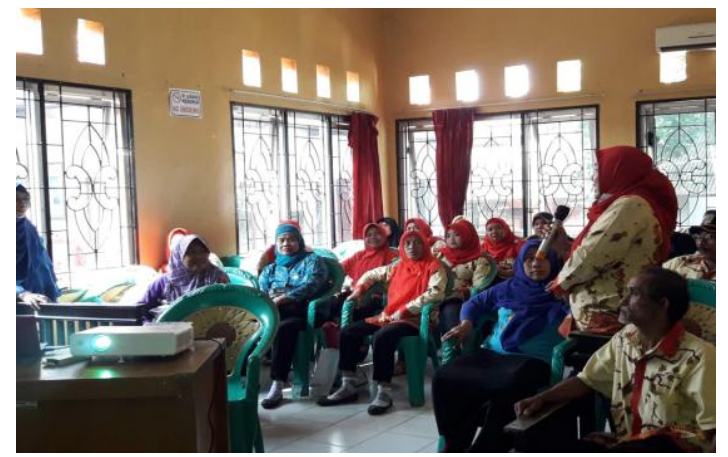

Gambar 2. Pembentukan Kader BKB

Metode lokakarya dengan memberikan pelatihan dan refreshing bagi para kader BKB, posyandu dan PAUD. Selanjutnya dalam kegiatan praktikum dengan memfasilitasi terlebih dahulu sarana pelayanan PAUD Holistik dengan investasi SDIDTK kit seperti tampak pada gambar 3 dan 4 .

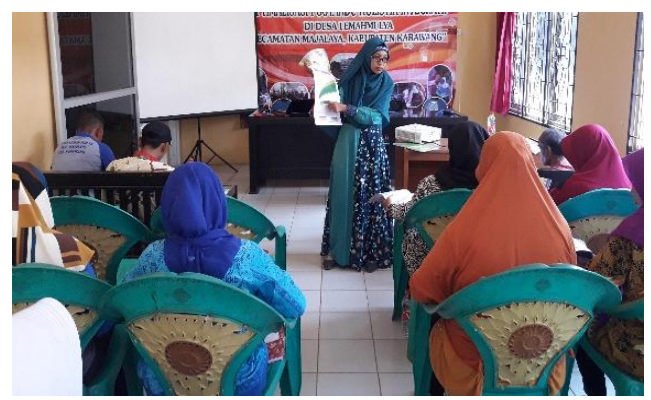

Gambar 3. Refreshing bagi kader dan guru PAUD

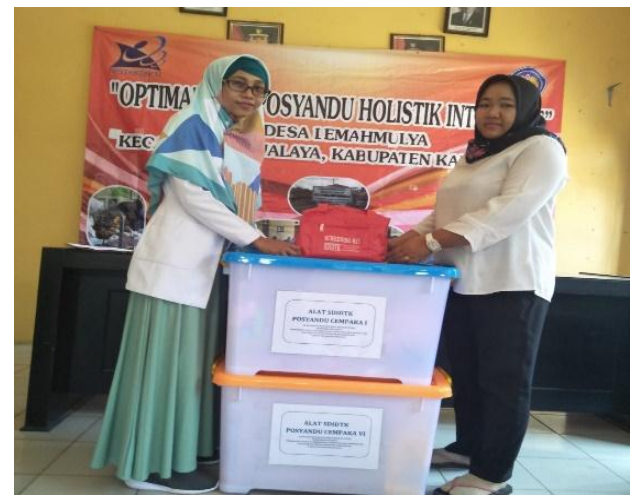

Gambar 4. Investasi Alat SDIDTK (APE)

Setelah pemberian materi baik teori maupun praktik, serta investasi alat SDIDTK, maka dilakukan metode perencanaan untuk mengimplementasikan pelayanan posyandu yang diintegrasikan dengan layanan PAUD dan BKB sesuai dengan tugas dan tanggungjawabnya.

\subsection{Tahap Monitoring dan Evaluasi}

Kegiatan pelaksanaan pengabdian dengan mengoptimalkan pelayanan PAUD yang diintegrasikan dengan pelayanan posyandu serta pembentukan BKB sebagaian bagian dari komponen yang diperlukan untuk mewujudkan kegiatan yang dilaksananakan setiap bulannya. Tahap ini merupakan tahap implementasi dari beberapa metode yang sudah direncanakan dan dipersiapkan. Melalui tahapan ini juga dapat dilakukan evaluasi dan monitoring dari apa yang telah dilakukan sebelumnya mulai dari persiapan, perencanaan dan pelaksanaan dengan beberapa metode. Hal ini juga dilakukan untuk mempersiapkan bahwa kegiatan selama pengabdian dapat dilaksanakan secara berkelanjutan, sebagaimana seperti pada gambar 5 sampai 7 .

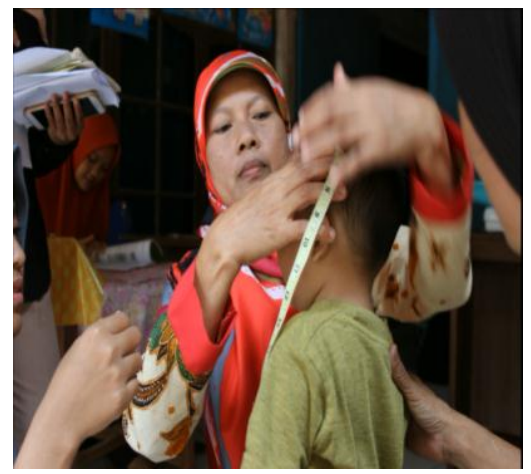

Gambar 5. Implementasi PAUD Holistik (pemantauan pertumbuhan)

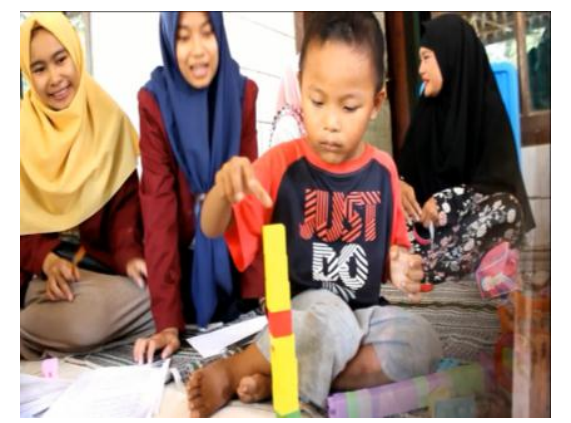

Gambar 6. Implementasi PAUD Holistik (pemantauan perkembangan)

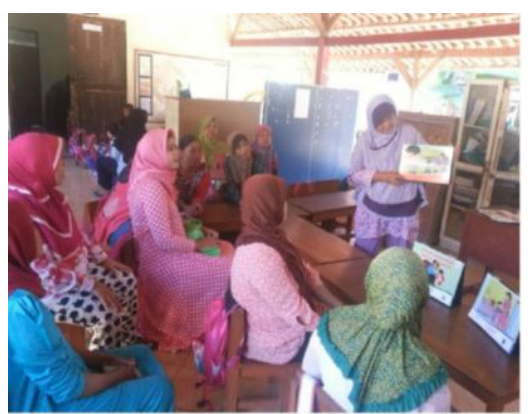

Gambar 7. Implementasi BKB 


\subsection{Tahap Analisis Data}

Metode pengumpulan dan analisis data pada kegiatan ini dengan memberdayakan para kader untuk mendapatkan data akurat jumlah balita di desa lemahmulya dan bekerjasama dengan bidan desa setempat serta guru PAUD. Pengumpulan data pengetahuan dan keterampilan para kader tentang pertumbuhan dan perkembangan dilakukan dengan menggunakan kuesioner, selanjutnya dianalisis menggunakan metode kuantitatif sehingga didapatkan distribusi frekuensi tentang pengetahuan pertumbuhan dan perkembangan balita seperti tampilan pada tabel 1 .

\section{Tabel 1. Pengetahuan Kader tentang Pertumbuhan dan Perkembangan serta Implementasi PAUD Holistik}

\begin{tabular}{|c|c|c|c|}
\hline No & Responden & Pretest & Postest \\
\hline 1 & A & 36 & 80 \\
\hline 2 & B & 34 & 82 \\
\hline 3 & C & 32 & 78 \\
\hline 4 & D & 42 & 81 \\
\hline 5 & E & 34 & 79 \\
\hline 6 & F & 42 & 80 \\
\hline 7 & G & 40 & 78 \\
\hline 8 & H & 28 & 78 \\
\hline 9 & I & 54 & 86 \\
\hline 10 & J & 28 & 82 \\
\hline 11 & K & 36 & 82 \\
\hline 12 & L & 32 & 80 \\
\hline 13 & M & 30 & 82 \\
\hline 14 & N & 22 & 71 \\
\hline 15 & O & 40 & 78 \\
\hline & Rata-rata & $\mathbf{3 5}$ & $\mathbf{8 0}$ \\
\hline
\end{tabular}

\section{PEMBAHASAN}

Terselenggaranya sosialisasi program dengan pihak terkait. Sosialisasi ini penting dilakukan untuk menjelaskan maksud dan tujuan dari kegiatan yang akan dilakukan kepada sasaran, agar saat pelaksanaan kegiatan tidak ada pertanyaan dari phak pihak tertentu dan yang paling utama harapannya dapat berpartisipasi aktif selama kegiatan berlangsung pasca diselenggarakannya sosialisasi program dengan pihak terkait.

Terbentuknya struktur kepanitiaan kader BKB pada mitra melalui SK kepala desa. Dengan adanya SK kepala desa tentunya merupakan bentuk legalitas bahwa pihak/orang tersebut memiliki tanggung jawab untuk melaksanakan tugasnya. Metode sosialisasi dan pembentukan tim BKB sebagai bentuk dukungan kepala desa dan tokoh masyarakat sejalan dengan penelitian kualitatif yang dilakukan oleh Sihombing dkk, mengenai Peran Lurah, Petugas Kesehatan dan Kader dalam Partisipasi Ibu Balita ke Posyandu di Wilayah Cakupan D/S Terendah dan Tertinggi di Kota Jambi yang menyatakan bahwa posyandu dengan cakupan tertinggi mendapatkan dukungan, motivasi dari pemangku kebijakan baik lurah, petugas kesehatan serta kader, sedangkan pada posyandu dengan cakupan terndah tidak (Sihombing dkk, 2015)
Refreshing bagi guru PAUD, kader posyandu dan BKB tentang SDIDTK dilakukan agar dapat membantu para kader dan guru PAUD untuk lebih memahami materi materi tentang SDIDTK karena bentuk penyampaianya adalah dengan mengulang beberapa yag telah tersampaikan dan memberikan pelatihan berupa materi baru dan praktikum mengenai SDIDTK.

Meningkatnya pengetahuan dan keterampilan para kader dan guru PAUD sebagai bagian dari masyarakat, tentang tumbuh kembang serta SDIDTK di tingkat pelayanan dasar dari 35\% menjadi $80 \%$. Setelah diberikan beberapa pelatihan mulai dari konsep tumbuh kembang sampai dengan mempraktikan cara mengidentifikasi masalah tumbang dengan menggunakan SDIDTK kit, terdapat peningkatan pengetahuan dan keterampilan tentang tumbuh kembang balita. Hal ini sejalan dengan pengabdian yang dilakukan oleh Alfiyanti $\mathrm{D}$, dkk mengenai Taman pintar Banana sebagai upaya Optimalisasi Kualitas Balita Desa Rowosari Kecamatan Tembalang Kabupaten Semarang dan dan Yuliani, I tentang pelatihan SDIDTK bagi guru PAUD dan wali murid PAUD yang menyatakan bahwa pemantauan tumbuh kembang balita yang masih belum optimal serta kurangnya pengetahuan masayarakat terutama ibu tentang pengasuhan bayi balita. Pengabdian ini menggunakan metode pelatihan kepada kader dan para $\mathrm{ibu/}$ masyarakat tentang stimulasi deteksi dan intervensi dini tumbuh dan kembang (SDIDTK) sebagai upaya pencegahan penyimpangan tumbuh kembang balita. Hasil menunjukkan dengan metode pendekatan pelatihan terdapat peningkatan pengetahuan dan keterampilan kader tentang SDIDTK

Kelompok sasaran mampu memberikan pelayanan SDIDTK kepada balita di wilayah kerjanya secara bertahap. Untuk mengoptimalkan dan memaksimalkan PAUD holistik dengan mempraktikan secara langsung dalam kegiatan pelayanan Posyandu yang diintegrasikan dengan PAUD dan BKB.

\section{KESIMPULAN}

Terlaksananya sosialisasi program pengabdian masyarakat di desa Lemahmulya Kecamatan Majalaya Kabupaten Karawang. Dukungan positif dari pemerintahan desa dalam pelaksanaan kegiatan program melalui kontribusi yang diberikan.

Upaya peningkatan pengetahuan keterampilan tentang pertumbuhan dan perkembangan bayi balita melalui refreshing kader dan guru PAUD pada bulan Juli-September, serta peningkatan pengetahuan dan keterampilan tentang tumbuh kembang bayi dan balita sebesar $80 \%$. Investasi SDIDTK kit untuk menunjang implementasi kegiatan program pengabdian.

Terlaksananya pelayanan PAUD Holistik di desa Lemahmulya Kecamatan Majalaya Kabupaten Karawang. 


\section{SARAN}

Kegiatan optimalisasi PAUD Holistik ini diharapkan dapat Saran untuk penelitian dengan judul atau topik yang mengacu kepada penelitian ini kedepannya dapat lebih baik lagi.

\section{DAFTAR PUSTAKA}

Alfiyanti D, Maryam, Rahayu, DA, IbM Taman Pintar Banana sebagai Upaya Optimalisasi Kualitas Balita Desa Rowosari Kecamatan Tembalang Kabupaten Semarang. Prosiding Seminar Hasil Penelitian dan Pengabdian, Jurnal Unimus, 2014.

Dewi CA, Zahraini DA, Sabarini S, Desain Pengembangan Anak Usia Dini Holistik Integratif PAUD Non Formal, Jurnal Penelitian PAUDIA Vol 2 No 1 Mei 2013

Hidayati U, Pendidikan Holistik Integratif di Roudhotul Athfal, Jurnal Pendidikan Agama dan Keagamaan, 2017, 241-262

Iswarawanti, N D, Kader Posyandu : Peranan dan Tantangan Pemberdayaannya dalam Usaha Peningkatan Gizi Anak di Indonesia .Jurnal Manajemen Pelayanan Kesehatan, Volume 13 No 4 Desember 2010 , 169-173.
Kementerian Kesehatan, RI, 2016, Pedoman Pelaksanaan Stimulasi Deteksi Intervensi Dini Tumbuh Kembang Anak di Tingkat Pelayanan Dasar ,Jakarta : Direktorat Kesehatan Keluarga Kementerian Kesehatan R I.

Sihombing K, Kandarina I, Sumarni, 2015, Peran Lurah, Petugas Kesehatan dan Kader dalam Partisipasi Ibu Balita ke Posyandu di Wilayah Cakupan D/S Terendah dan Tertinggi di Kota Jambi, Jurnal Gizi dan Dietetika Indonesia. Vol 3 No 2 (87-97)

Yuliani I, 2018. Pelatihan Stimulasi Deteksi Intervensi Dini Tumbuh Kembang (SDIDTK) bagi para guru dan wali murud PAUD pada PAUD Baitunnur Gentan Sinduharjo Ngaglik Sleman. Jurnal Pengabdian Dharma Bhakti Volume 1 No 1.

\section{UCAPAN TERIMA KASIH}

Terimakasih atas dukungan dan sumber pendanaan yang diberikan dari Direktorat Riset dan Pengabdian kepada Masyarakat, Direktorat Jenderal Penguatan Riset dan Pengembangan Kementerian Riset, Teknologi dan Pendidikan Tinggi dengan nomor Perjanjian Kerjasama : 051/SP2H/PPM/DRPM/2018. 